\section{Postpartum haemolytic-uraemic syndrome successfully treated with antithrombin III}

Since first described in 1966 the acute postpartum haemolyticuraemic syndrome (HUS) has been reported in over 40 cases by various authors. ${ }^{1}$ In view of the poor prognosis despite treatment with dialysis, immunosuppression and heparin, streptokinase, dipyridamol, acetylsalicylic acid, or corticosteroids, alone or combined, we report a case in which treatment with a concentrate of antithrombin III (AT-III) appeared to cure the haemolytic anaemia and the thrombocytopenia rapidly, normalise kidney function within a few days, and prevent irreversible kidney damage.

\section{Case report}

A 34-year-old primipara was admitted to hospital in the eighth month of pregnancy because of a slightly raised blood pressure $(150 / 100 \mathrm{~mm} \mathrm{Hg})$ and proteinuria $(1 \cdot 5-4 \mathrm{~g} / 24 \mathrm{~h})$. Thirty hours before delivery her serum creatinine was $277 \mu \mathrm{mol} / 1(3.1 \mathrm{mg} / 100 \mathrm{ml})$. Four days after admission labour began spontaneously and was completed in 70 minutes without complications.

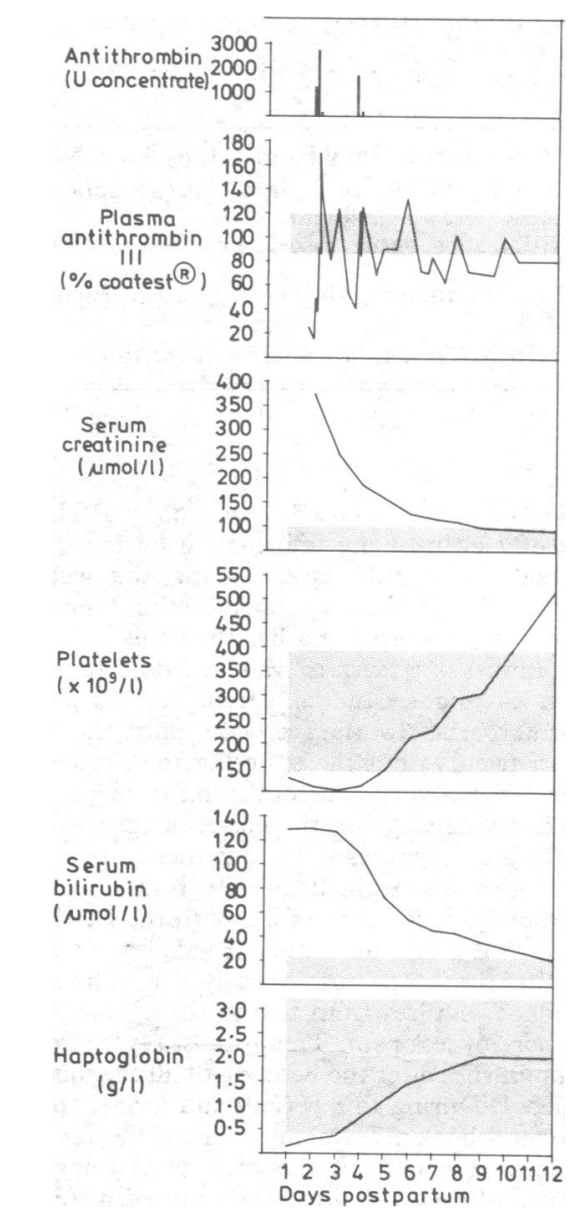

Course of postpartum haemolytic-uraemic syndrome during treatment with antithrombin III concentrate. Shaded areas represent normal range.

Next day the patient became dyspnoeic with generalised pain, slight icterus, and macroscopic haematuria. Blood pressure and temperature were normal. Radiographs of lungs and an electrocardiogram were normal. Serum creatinine and bilirubin concentrations rose, moderate thrombocytopenia developed (phase contrast microscopy), and haptoglobin (immundiffusion method) decreased (figure). Reticulocytes increased to $5.7 \%$ and haemoglobin concentration fell in 48 hours from $11.1 \mathrm{mmol} / 1(12 \mathrm{~g} / \mathrm{dl})$ to 8.2 $\mathrm{mmol} / 1(8.9 \mathrm{~g} / \mathrm{dl})$. Coombs test was negative. Catheterisation 24 hours after delivery produced $1000 \mathrm{ml}$ urine.

The plasma AT-III concentration (Antithrombin Coatest) was very low (figure). Therefore 26 hours after delivery treatment was begun with a concentrated solution of AT-III prepared from a purified preparation of human AT-III (Kabi, Stockholm). First 1200 units of AT-III were given as an intravenous bolus (one unit was equivalent to the amount of AT-III $/ \mathrm{ml}$ normal human plasma). One hour later 2750 units were infused over a period of three hours, followed by a third infusion of 250 units (figure). The AT-III concentrations were unstable. $A$ fall on the third day required an additional infusion of 1650 units over four hours followed by a bolus injection of 150 units, and the concentration stabilised at a slightly subnormal level. During and after the AT-III infusions serum creatinine and bilirubin concentrations fell while haptoglobin and platelets soon returned to normal (figure), as did the patient's clinical condition. Kidney biopsy on the 10th day showed normal morphology. Five months later kidney function was normal and haemoglobin and AT-III concentrations were in the lower range of normal.

\section{Comment}

The aetiology of HUS is unknown, but our data suggest that a stage of disseminated intravascular coagulation (DIC) is a factor of pathogenetic significance. ${ }^{1}$ Quite possibly thromboplastin escapes from the thromboplastin-rich placenta by uterine contraction during labour. Also in pregnancy sensitivity is increased to stimuli known to induce DIC. ${ }^{2}$ Interestingly infusion of AT-III can protect chicken embryos against the injection of thromboplastin. ${ }^{3}$ Similarly, heparin is reported to prevent the toxicity of thromboplastin injection in mice. But heparin increases the turnover rate of AT-III, ${ }^{4}$ and giving heparin to patients low in plasma AT-III may therefore paradoxically increase an existing risk of thrombosis. ${ }^{5}$ Therefore the low plasma AT-III concentration at the onset of the syndrome in our patient seems particularly significant, and we believe her recovery was due to the treatment with AT-III concentrate.

We thank Dr T Astrup, the University Centre of South Jutland, for valuable advice, and Professor Steen Olsen, University Hospital, Århus, for the kidney biopsy. Support was received from the funds for medical research in the counties of Ringkobing, Ribe, and Sønderiylland, and from Kabi Research Laboratories and Kabi Diagnostica (Stockholm) and Løven Pharmaceuticals Ltd (Copenhagen).

1 Strauss RG, Alexander RW. Postpartum hemolytic uraemic syndrome. Obstet Gynec 1976;47:169-73.

${ }^{2}$ Hardaway RM. Syndromes of Disseminated Intravascular Coagulation. Springfield: Thomas, 1966.

${ }^{3}$ Mann LT, Jensenius JC, Simonsen M. Antithrombin III: protection against death after injection of thromboplastin. Science $1969 ; 166: 517-8$.

- Collen C, Schetz J, Cock FD, Holmer E, Verstraete M. Metabolism of antithrombin III (heparin cofactor) in man: effects of venous thrombosis and of heparin administration. $\mathcal{f}$ Clin Invest $1977 ; 7: 27-35$.

5 Marciniak E, Gockerman JP. Heparin induced decrease in circulating antithrombin III. Lancet 1977 ;ii:581-4.

(Accepted 7 November 1979)

Medical Department, Department of Obstetrics and Gynaecology and Department of Clinical Chemistry, Esbjerg County Hospital, 6700 Esbjerg, Denmark

PER BRANDT, MD, senior registrar

JØRGEN JESPERSEN, MD, senior registrar

GUNNAR GREGERSEN, MD, DRMED, consultant

\section{Blood concentrations of dihydroxylated vitamin $D$ metabolites after an oral dose}

Dihydroxylated vitamin D metabolites are being used increasingly in clinical medicine. We therefore measured blood concentrations of these compounds in normal subjects after single oral doses of $1,25-$ dihydroxycholecalciferol $\left(1,25-(\mathrm{OH})_{2} \mathrm{D}_{3}\right)$ and 24,25-dihydroxycholecalciferol $\left(24,25-(\mathrm{OH})_{2} \mathrm{D}_{3}\right)$.

\section{Subjects, methods, and results}

Four normal volunteers (three men, one woman) were given $4 \mu \mathrm{g} 1,25$ $(\mathrm{OH})_{2} \mathrm{D}_{3}$ after an overnight fast. Three normal volunteers (two men, one woman) were given $250 \mu \mathrm{g} 24,25-(\mathrm{OH})_{2} \mathrm{D}_{3}$ (in $0.5 \mathrm{ml}$ ethanol) after an overnight fast. Blood was taken at the times indicated (see figure) and the serum stored at $-20^{\circ} \mathrm{C}$. Serum concentrations of both metabolites were measured in each person by a method ${ }^{1}$ which gives a range of 29-168 pmol/1 for $1,25-(\mathrm{OH})_{2} \mathrm{D}_{3}$ and a range of $2 \cdot 9-16 \mathrm{nmol} / 1$ for $24,25-(\mathrm{OH})_{2} \mathrm{D}_{3}$. 